\title{
Computational Statistics on Stress Patients with Happiness and Radiation Indices by Vedic Homa Therapy: South Asian Heritage with Scientific Aspects in Global Pandemic
}

\section{Rohit Rastogi ${ }^{1 *}$, Sheelu Sagar ${ }^{2}$, Neeti Tandon ${ }^{3}$, Rajeshwari T ${ }^{4}$ and Bhavna Singh ${ }^{5}$}

${ }^{1}$ Sr. Asst. Professor, Department of CSE, ABES Engineering College Ghaziabad, Uttar Pradesh, India

${ }^{2}$ Research Scholar, Amity International Business School, Amity University, Noida, Uttar Pradesh, India

${ }^{3}$ Research Scholar, Vikram University, Ujjain, Madhya Pradesh, India

${ }^{4}$ Yagyopathy Researcher and Active Social Volunteer, Kolkata, West Bengal, India

${ }^{5}$ Professor, Materia Medica \& Ayurvedic Pharmacology, Uttaranchal Ayurvedic College, Dehradun, Uttarakhand, India

*Corresponding author: Rohit Rastogi, Sr. Assistant Professor, Department of CSE, ABES Engineering College, Ghaziabad, Uttar Pradesh, India, Tel: +91-8076772048; Email: rohit.rastogi@abes.ac.in

\section{Abstract}

The Happiness Programs and seeking its various means are popular across globe. Many cultures and races are using it in different ways through Carnivals, festivals and occasions. In India, the Yajna, Mantra, Pranayama and Yoga like alternate therapies are now drawing attention of researchers, socio behavioral scientists and philosophers by its scientific divinity. The present manuscript is an honest effort to identify the logical progress on happiness indices and reduction in radiation of electronic gadgets. The visualizations propound evidences that the Ancient Vedic Rituals and Activities were much effective in maintaining the mental balance. The data set was collected after a specified protocol followed and analyzed through various scientific data analysis tools available.

Keywords: Yajna; Mantra; Stress; Depression; Anxiety; Mental Fitness

\section{Introduction}

\section{Pregnancy and Issues with Global and Indian Females related to Health}

Many scientific studies have now shown that if a mother is stressed, anxious or depressed while pregnant, her child is at increased risk for having a range of diseases like ADHD, conduct disorder and impaired cognitive development, including emotional problems. Thus it is important to keep a healthy body with a healthy and peaceful mind during natal and prenatal stage [1].
Women's health during the reproductive or fertile years (between the ages of 15 and 49 years) is relevant not only to women themselves but it also impacts on the health and development of the next generation. Pregnancy and childbearing are especially risky for women who have high blood pressure, high cholesterol levels, tobacco use, obesity, which are the very common resultant of modern lifestyle. These factors contribute to poor reproductive outcomes for both mother and infant and are direct causes of other health problems for women. Another main cause is malnutrition and especially anemia which make various complications 
during pregnancy. More than half a million maternal deaths occur every year and, of these, 99\% happen in developing countries [2].

However, there is nothing inevitable about these deaths. In industrialized countries, there are on average nine maternal deaths per 100,000 live births, whereas this figure can be as high as 1000 or more per 100000 live births in the most disadvantaged countries. In settings where high fertility is the norm, women face such risks with each pregnancy. With the appropriate care, maternal mortality is in fact a very rare event $[3,4]$.

On account of modernization and urbanization, different kinds of changes in our lifestyle are the main cause of most of the gynecological disorders and infertility is also one of them. Infertility has become a very challenging problem for working class ladies as well as common housewives. Many lifestyle factors such as the age at which to start a family, nutrition, weight, exercise, psychological stress, environmental and occupational exposures, can have substantial effects on fertility. Other lifestyle factors such as cigarette smoking, illicit drug use, and alcohol and caffeine consumption can negatively influence fertility [5].

All these factors are associated with a range of poor pregnancy outcomes, including reduced fertility, an increased risk of pregnancy complications and impaired infant and child development. It has been estimated that the number of infertile people in the world may be as high as $15 \%$, particularly in industrialized nations [6] (Figure 1).



Figure 1: Garbhasth Gayatri Mantra, a Rhythmic group of Syllabels for pregnant ladies to protect the womb.

\section{Pain and its own world}

Studies have shown that the mantra chanting, meditation, Pranayama, Yoga and other practices are much useful for all the humans of different age groups, especially to females and aged persons. For females, pregnant ladies are specially getting immense benefit for themselves as well as for their baby in their womb [7].

Scientific experiments are being conducted with help of different sensors and latest electronic gadgets to record the benefits of Yajna, mantra and meditation over these issues (Pl. refer Figure 2 and Figure 3).

(A World of Pain", National Geographic Magazine, vol. 1, issue-1, pp. 32-57, (January 2020)), Source:https://www. nationalgeographic.com/magazine/2020/01/scientists-areunraveling-the-mysteries-of-pain-feature/

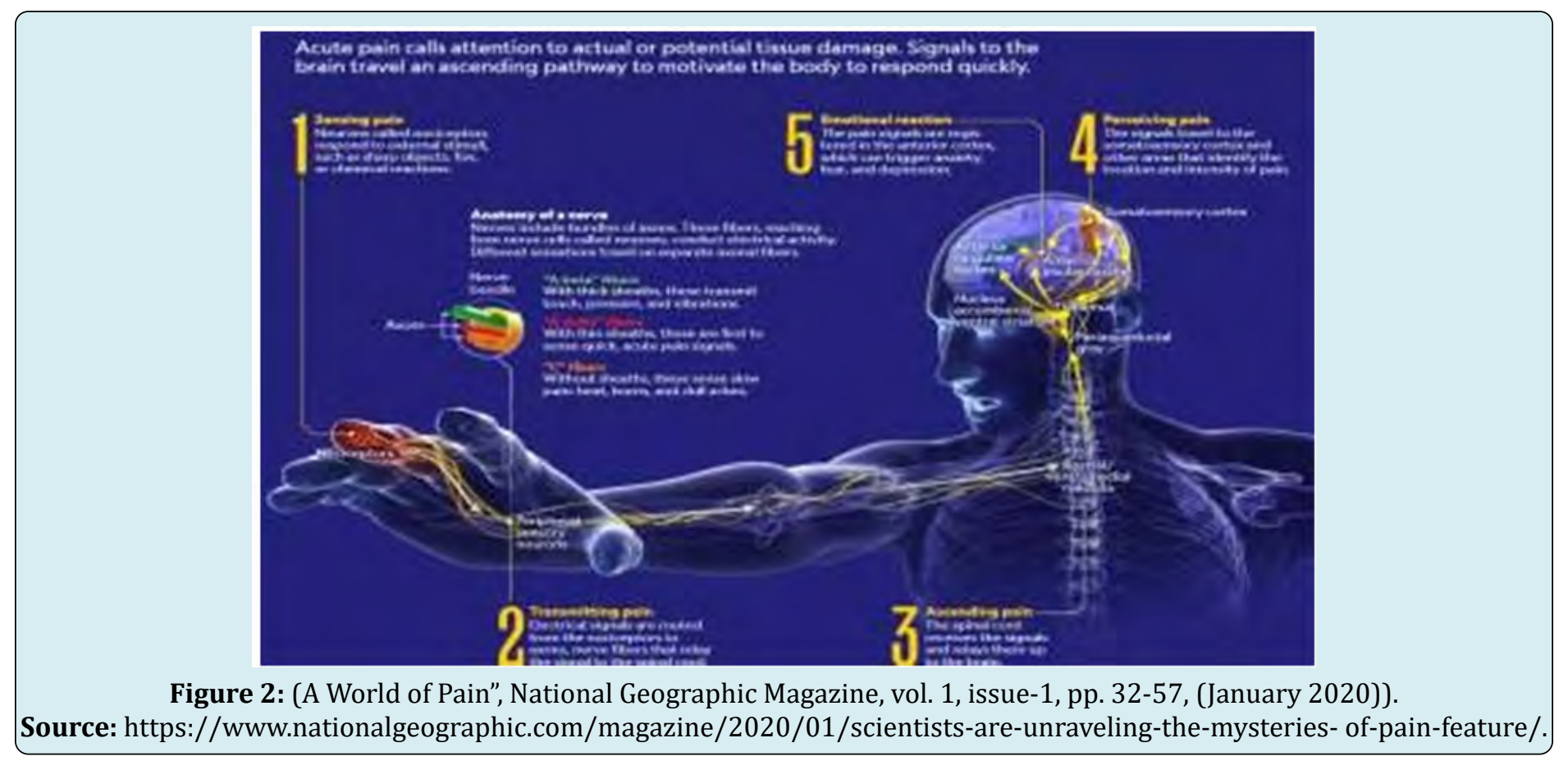




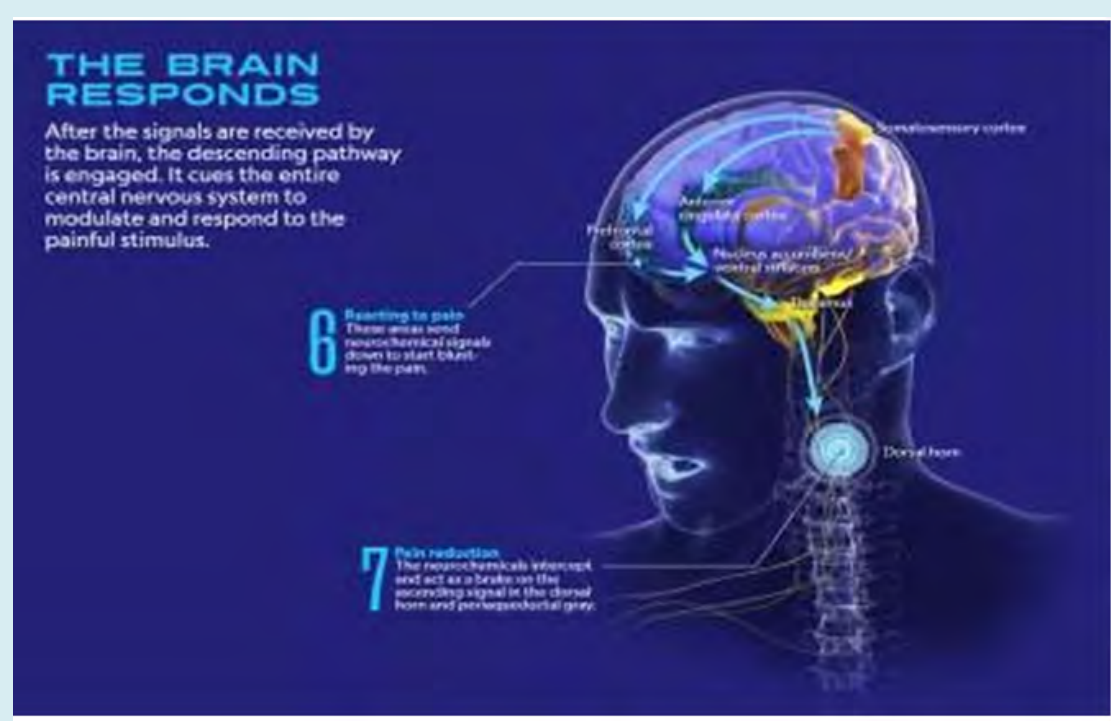

Figure 3: (A World of Pain", National Geographic Magazine, vol. 1, issue-1, pp. 32-57, (January 2020)).

\section{Chemical Property of Ghee (Clove Butter)}

Chemically, Ghee is essentially composed of a mixture of triglycerides extracted from acidic acids such as polymitic, oleic, meristic and stearic. The composition of fatty acid of ghee varies according to the diet of the animal producing it. The Reichert-Missal or Reichert-Wolney number is important in calculating the amount of these acids in the whole balanced ghee [8].

\section{Chemical Organization of Ghee}

Approximately $98 \%$ triglyceridase in ghee, $1-2 \%$ diglyceridus, $\quad 0.1-0.2 \%$ monoglycera-eidus, $1-10 \mathrm{mg} /$ $100 \mathrm{gm}$ Ghee free fatty acid (FFA), 0-80 mg / $100 \mathrm{gm}$ phospholipidase, $0.25-0.40 \%$ cholesterol and in small amounts, fat soluble vitamins, carbonyl, glyceryl ether and alcohol are found. About 500 fatty acids are found in hGhee, most of which are found to have even-numbered carbon chains (C4-18). Polyunsaturated Fatty Acids are found in $3-4 \%$ in Ghee $[9,10]$.

Butyric, palmitic, stearic, tetranoic and pantanoic acids are found in buffalo ghee more than cow ghee. The acid of the series from caproic to myrrheic is found in cow's ghee more than buffalo ghee (Pl. refer Figure 4).

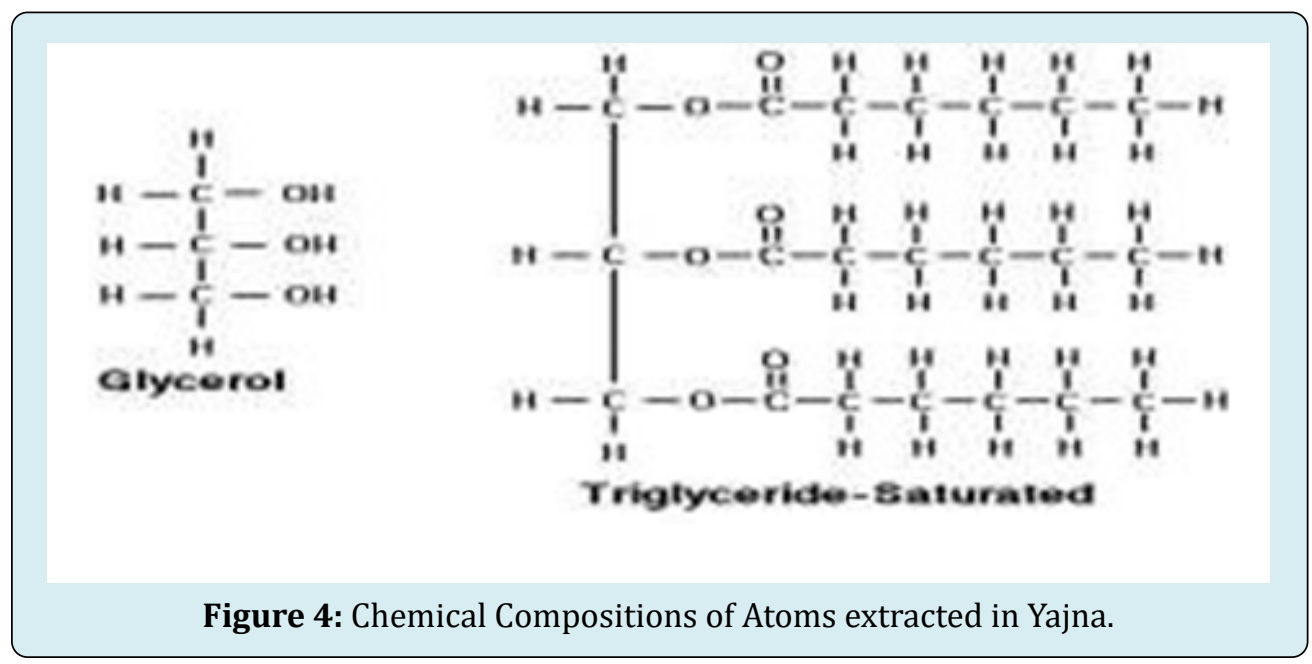

\section{Composition of Fats}

Simple triglycerides are those in which each molecule of glycerol is combined with three molecules of one acid-e.g., tripalmitin, $\mathrm{C}_{3} \mathrm{H}_{5}\left(\mathrm{OCOC}_{15} \mathrm{H}_{31}\right) 3$, the glyceryl ester of palmitic acid, $\mathrm{C}_{15} \mathrm{H}_{31} \mathrm{COOH}$. 


\section{Journal of Natural \& Ayurvedic Medicine}

\section{SUCROSE STRUCTURE}

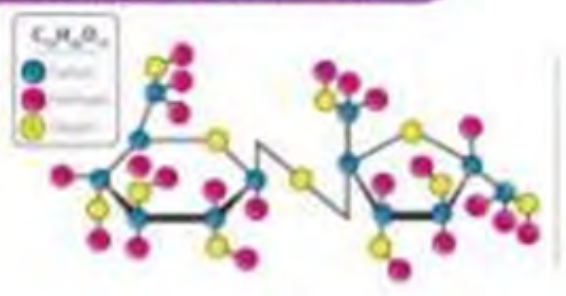

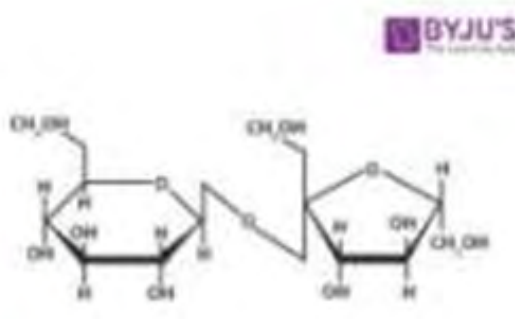

Figure 5: Molecular Structure of Sucrose.

Sugar is sucrose, a molecule composed of 12 atoms of carbon, 22 atoms of hydrogen, and 11 atoms of oxygen $\left(\mathrm{C}_{12} \mathrm{H}_{22} \mathrm{O}_{11}\right)$. Like all compounds made from these three elements, sugar is a carbohydrate (Pl. refer Figure 5).

In this way, by sacrificing Yajna, oxygen is not spent but is emitted / produced. At the same time, the environment is purified by Gaseous products made from other chemical reactions and we also get health benefits $[11,12]$. The remaining ash of Agnihotra increases the fertility of our soil and also works to remove some skin diseases. So there is no harm but benefit from the sacrifice. Yagya in the house every day and organize big yagyas on festivals, then the world can be free from diseases (Figure 6).

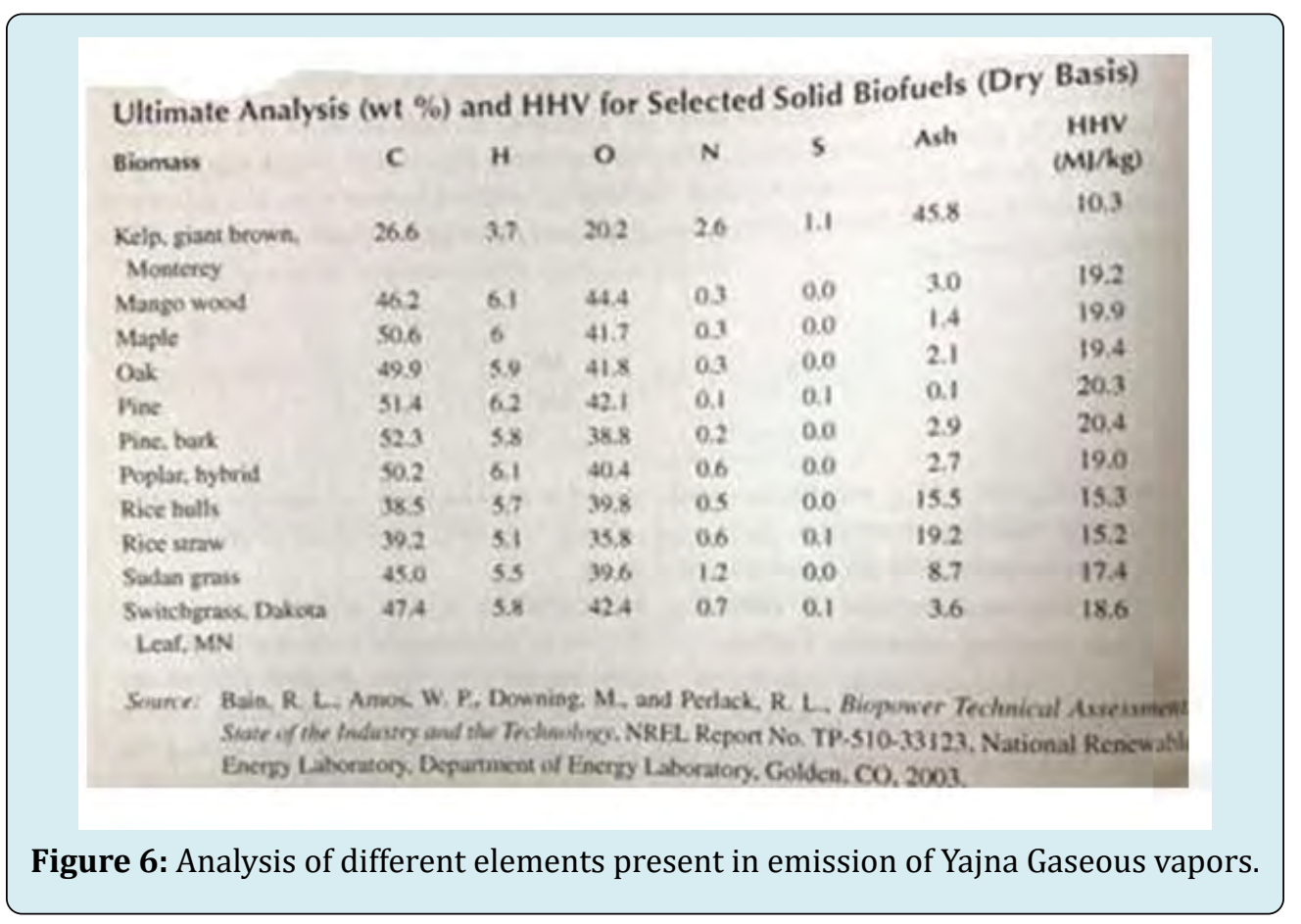

\section{Yajna with Cow clove produces Oxygen}

One misconception that is prevailing about Yajna that Yajna with Desi Cow's ghee produces $\mathrm{x}$ tons of oxygen. Solution-This is not correct. If at all some oxygen is produced it is produced by photochemical reactions as an interim product which is again consumed in the process.

- The end products are largely $\mathrm{CO} 2$ and water vapors.
- This CO2 when escapes in atmosphere are absorbed by plants and trees which in turn give out Oxygen. But this is their usual activity $[13,14]$.

- We have observed in our logical and scientific experiments that the level of oxygen is maintained if Havan is done with Gomay Samidha as they have a large amount of oxygen trapped inside (Pl. refer Figure 7). 


\section{Journal of Natural \& Ayurvedic Medicine}

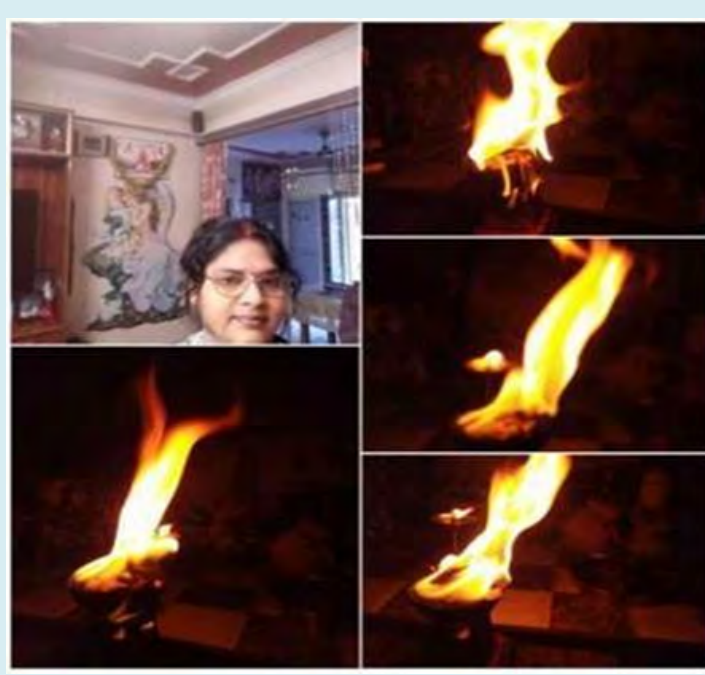

Figure 7: Yajna Ceremony performed by Volunteers at their home or public places like Temples

Many countries of the world have done research on Gayatri Mantra and the results they got were surprising. Hence, Gayatri Mantra is the reason the world's most powerful mantra. https://youtu.be/CrwTLrN2q60.

\section{Literature Survey}

Scientific Aspects of Yajna and related Doubts are presented here. Usually there is a myth and doubt that there is smoke from Yagya, which increases air pollution and oxygen is also spent because something burns only when it gets oxygen. Clarification and solution to this is that there is no pollution by sacrificial fire. It increases more than the amount of oxygen spent. Pollution is cured.

-Yagya is a completely scientific process.

- It is the best act.

- There is no better work than Yagya

- Yajna is also called Agnihotra or Havan.

- Agnihotra means the sacrifices made for the purification of water, earth, air, etc.

- Yajna is not only ritual, but also a medical practice. The various chants that we perform while performing the Yajna have a special effect on our mind, brain, and soul. It also purifies the atmosphere.

- Yajna is also called Havi which means one who defeats poison. According to the theory of science, no substance is destroyed, but yes its form can be changed.

- Havan Ingredients are the ghee of cow etc. which we put on fire, they are like medicines for Havan, they are not destroyed by burning, but are converted to another form and we get it in subtle form. When there was no allopath, there was Aayurved in ancient times. In Aayurved, it was only from these plants that treatment was done.
Among the medicines which are in the incense material, they have qualities like:

1. Disinfectant

2. Aromatic Enhancer

3. Medicinal Action Property

4. Nutritious. 5. Oxygen Booster

When these medicines are burnt in the Havan Kund, they reach not one, but many living animals through the breath in atomic form, which also helps them. The following are the chemical activities in the Yajna.

1. Combustion

2. Sublimation

3. Fumigation Is A Method Of Pest Control That Completely Fills An Area With Smoke, Vapor, Or Gas To Deliver For The Purpose Of Disinfecting Or Of Destroying Pests.

4. Volatilization: Volatilization is the process whereby a dissolved sample is vaporised.

All these chemical activities are beneficial for us. In these, cow's ghee (containing about 8\% saturated Fatty Acids and Triglycerides, Diglycerides, Monoglyceride) during combustion reaction intensifies the combustion leading to Complete Combustion. $\mathrm{CO}_{2}$ and $\mathrm{H}_{2} \mathrm{O}$ are released during the combustion of Fatty Acid. Complete Combustion also reduces $\mathrm{CO}_{2}$. Pyruvic Acid and Glyoxal $\left(\mathrm{C}_{2} \mathrm{H}_{2} \mathrm{O}_{2}\right)$ are formed in the combustion of glycerol. Pyruvic Acid increases our metabolism and kills Glyoxal $[15,16]$.

Apart from these, the hydrocarbons that are formed during combustion again go through slow combustion reaction and form methyle, ethyle alcohol, formic acid and formaldehyde etc. which smells like air and is disinfectant. It also has the ability to eliminate H1N1 virus. Now you must be thinking that oxygen is spent when ignition and in a way we harm the environment. But you are wrong. Yajna is the process in which oxygen is spent but oxygen is also produced, as it also produces vapor $\left(\mathrm{H}_{2} \mathrm{O}\right)$ along with $\mathrm{CO}_{2}$.

$$
\mathrm{CO}_{2}+\mathrm{H}_{2} \mathrm{O}(\mathrm{G})+112000 \mathrm{Cal}=\mathrm{HCHO}(\text { Farmaldehyde })+\mathrm{O}_{2}
$$$$
\text { (Oxygen) }
$$

It is certain that whenever anything burnt, Oxygen will be absorbed and carbon will be emitted. But there are vast difference in carbon emitted by garbage burning and carbon emission from burning fragrant. Commonly accepted philosophical factors that antidote to a poison is, also a poison derived from another resource. Similarly smoke and poisonous gases emitted by burning garbage, can be reversed back by the fumes produced by aromatic herbs that are offered in the Yagya as oblations (Aahutis).

The carbon that emits during Yagya, through aromatic herbs are in very little amount that are considered 
necessary to activate certain neurons in the system. Apart from the herbs that are offered in the fire which produces qualities environmental friendly gases, creosote, phenols, acetylene, aldehyde and ozone too assimilate in this. Even if any poisonous substance emitted on a little quantity is immediately evaporated with the oblations given by clarified butter (Ghee) and makes it non-poisonous.

\section{Experimental Setup and Methodology}

The Experiments to support the science of Yajna and Mantra were conducted through a well-defined protocol of 45 minutes where the Mantra Chanting, Pranayama, Yoga and Fitness activities were carried out. The laughing therapy and some alternative therapies like acupressure, Pranik Healing were also used in different time intervals.

\section{Protocol Followed}

The readings were being recorded by research team members quantitatively under different parameters and analyzed through various data analytics tool like Python, Tableau, SPSS, and excel. The subjects were asked to fill a small consent form to give their will to participate in the aforesaid experiments and were assured that their identity and data will not be made commercial and misused [17-19].

The whole experiment was conducted through online platforms like Google meet, Zoom sessions, MS Team etc. as per convenience of the subjects during the lockdown period and their scores were recorded. The activities were conducted in India of duration of pandemic Sars-Cov'19 peak of $1^{\text {st }}$ April 2020 to $31^{\text {st }}$ Aug. 2020 in the period of 150 days around where a strict lockdown was imposed in India to save the mass from third stage infection of spread of Sars Cov'19.

The Subjects were asked to follow a strict protocol of 45 min. around which included some Asans ( sitting, standing, lying front and back postures), some set of Mantra Chanting, Breathing Exercises( Pranayam), Alternate Therapies like Laughing Technique and Shantipath with certain breathing Exercises were followed. Subjects' data was recorded pre and post of the experiment and accordingly comparative study was conducted to check the efficacy of the methodology adopted [20-22].

\section{Scientific Experiments on the Ash of Yajna and Chemical Analysis-T Rajeshwari Di}

Pl. see Annex for Permission Letter and Scientific Analysis of Different components in the Ash of Yajna Pinch of consumption of Yagya bhasm as Prasad, was questioned by a person, that created an inquisitiveness which lead to do an experiment on Yagya to understand the components contained in Yagya bhasm, and its composition. With proper letter issued from Sunderpur, Jabalpur, MP. GAYATRI SHAKTIPEETH was sent to Geological survey of India, through Mr. Jayant Gupta of Gayatri Pariwar of Jaipur (Youth wing), an executive at GSI. He approached their director and research on Yagya bhasm was executed with approval. We extend our heartfelt gratitude to all, who put their efforts to conduct this research and released the appropriate report.

Some scientists from BARC have also agreed to do research on the Yagyaagni. They are interested to study the flames of Yajna beginning temperature, gases released, temperature in the middle and its intensity with gases released, and temperatures at the end when the flames are off with the gases released [23-25].

\section{Results and Discussion}

\section{Happiness Index of Human and Radiation Analysis of Gadgets Analysis}

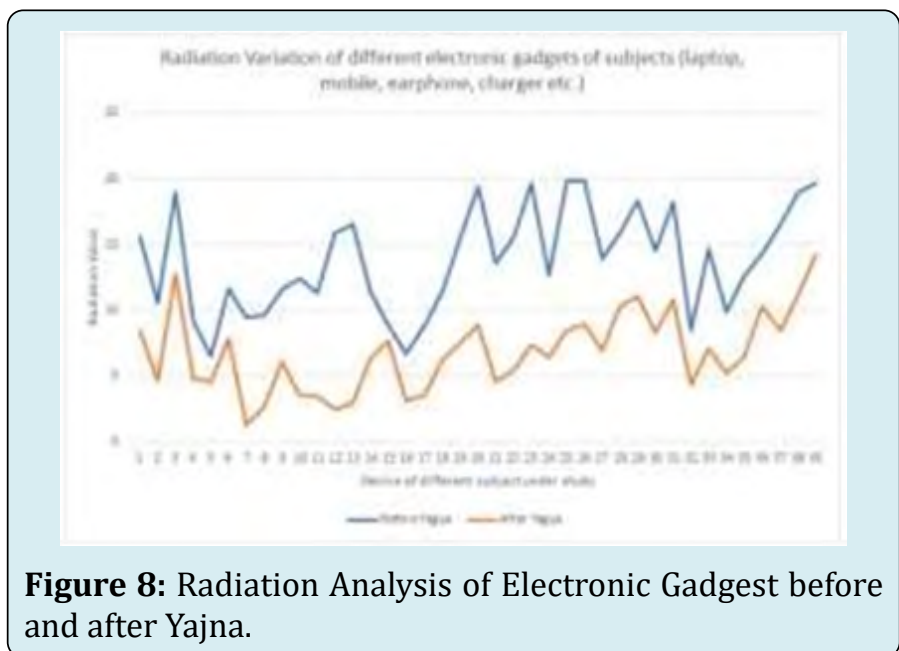

The electronic gadget like mobile, laptop, charger etc. radiations were recorded significantly low after the Yajna Process than before Yajna Rituals (Figure 8).

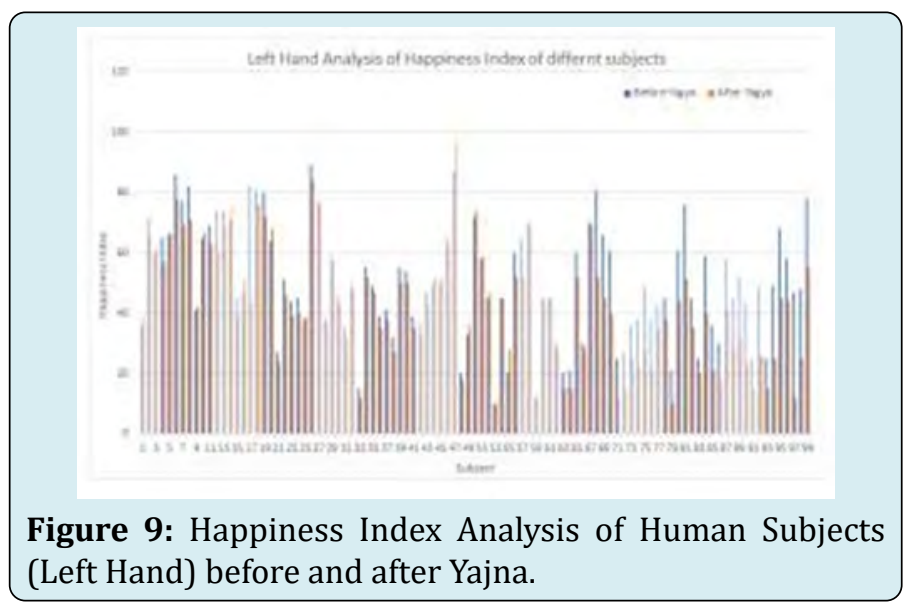


If see and analyze the graphs critically that we can easily see that red graph(After Yajna) is continuous below to blue(Before) graphs through left hand readings which shows the reduction in stress level and increase in happiness Index measured by Happiness Meter of the subjects participated in Yajna Ceremony and chanting of mantra (Figure 9).

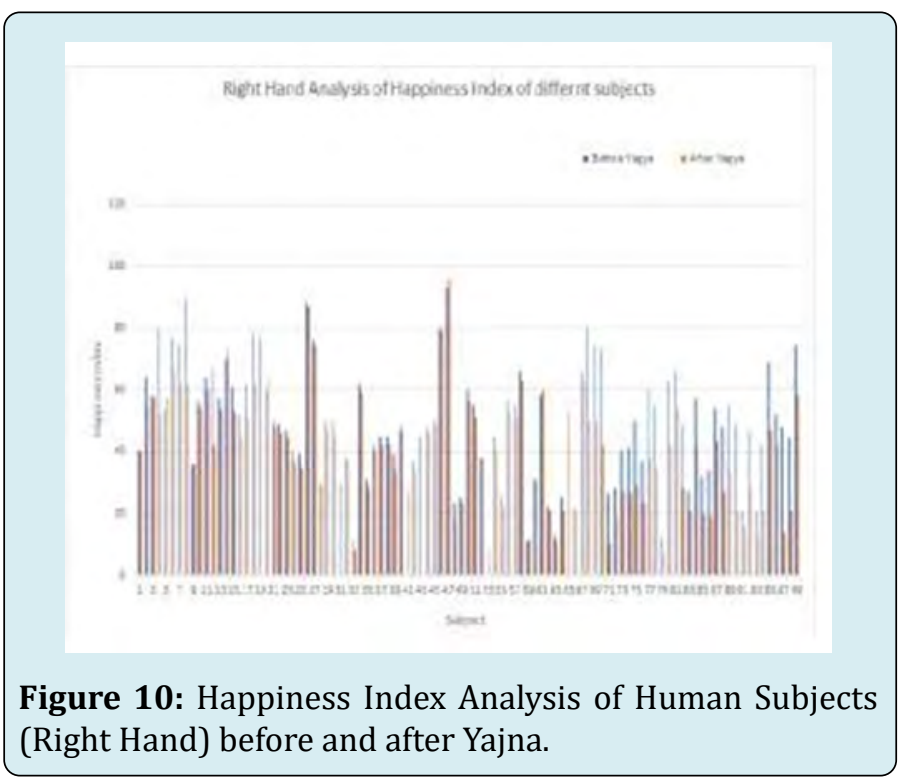

If see and analyze the graphs critically that we can easily see that red graph(After Yajna) is continuous below to blue(Before) graph through right hand readings which shows the reduction in stress level and increase in happiness Index measured by Happiness Meter of the subjects participated in Yajna Ceremony and chanting of mantra (Figure 10).



The participants Happiness counted through right hand w.r.t age is reflected above and shows that there is significant fluctuation in happiness index as per increasing rate of age. It totally depends on mental fitness, cool and calf life style and inner strength (Figure 11).

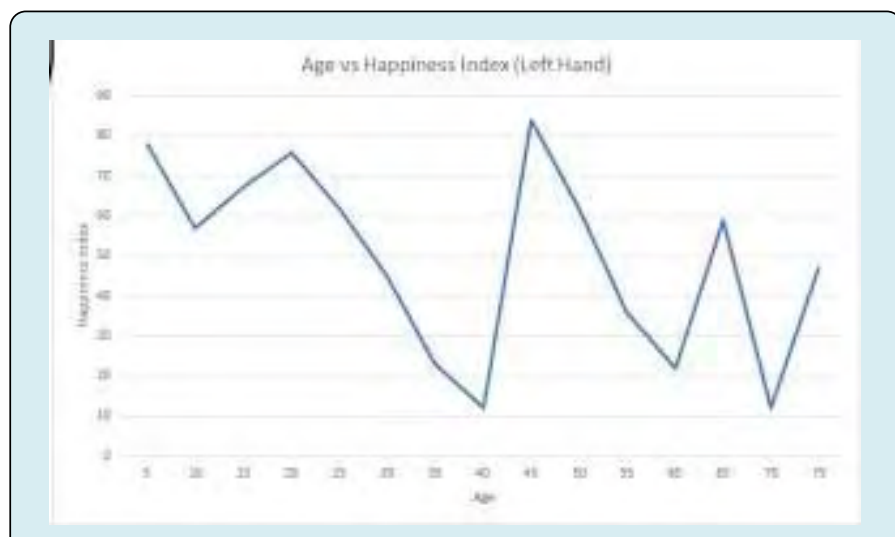

Figure 12: Age vs. Happiness Index Analysis of Human Subjects (Left Hand) in Yajna.

The participants Happiness counted through left hand w.r.t age is reflected above and shows that there is significant fluctuation in happiness index as per increasing rate of age. It totally depends on mental fitness, cool and calf life style and inner strength (Figure 12).

\section{Recommendations}

The main recommendations from Indian culture is Yagya Pita- Gayatri Mata (Yajna Father, Gayatri Mother). According to science, heat, sound and light have been the fundamental units of power. Mantra is only the sound. The word is expected to travel at the speed of heat and light. To make the mantra wider, heat and light have to be combined with it as Yagya, only then it becomes more powerful and universal (Knowledge of Yagya, science, Yugrishi Shriram Sharma Acharya) [11].

One of the main reasons is said to be the delay in enforcing restrictions in Italy. After China, Now it is fully blown up epidemic in Italy and Spain and it is moving to other European countries as declared by WHO. This is third stage in Italy and Europe and second stage in USA. In India, we are passing through $11^{\text {st }}$ stage and $2^{\text {nd }}$ stage is very near. China has shown the way to the world [26-30].

\section{Novelty}

Yagyopathy was an integral part of the Vedik Period and it was vanished during the medieval period. Now the Yagyopathy has been developing as a Yagya Therapy for solving various issues. Evoking of the Inner power, Establishment of Spiritual Environmental place, development of wholesome culture, cleansing of micro environment, benefit on humanity are various new domains which are ipening for human race. The need is to get the benefit and explot this knowledge to 


\section{Journal of Natural \& Ayurvedic Medicine}

address the current threats for this planet [31,32].

\section{Future Research Directions}

Many more research is needed in the domain of Meditation with Pranayama. Diseases are caused by the weakness of life force. Power comes in the body due to the strength in life. It is impossible to happen that power comes in the soul due to strength in the body. That is why it is said that Pranayama (the action- which exercises the souls and which makes the soul strong) increases age and sage muni by this will. They used to live long (Yajna: a holistic healing process, Yugrishi Shriram Sharma Acharya).

Divine powers strengthened to destroy demonic powers, to force the constructive powers (Yajna is a means: a holistic healing process, Yugrishi Shriram Sharma Acharya) [33-35].

\section{Conclusion}

Aim of Yajna science is for many dimensions in which the main aspects are fortification and balance of environment, rain of water with energy (Pranik Urja), improvement of health, treatment of illness, reviving through Yagyopathy. Param Pujya Pt. SriRam Sharma Acharya ji, founder of All world Gayatri Parivar, revived the Yajna and Yagyopathy. Brahmvarchas research Center and Shantikunj Haridwar are conducting researches from past 40 years. Dev Sanskriti University Haridwar was added as a feather in its cap in year 2002. Several PhDs and research works are being enlightened in the field of human consciousness upliftment through ancient Vedik Sciences for Human Health and Environment is being conducted here.

The present Manuscripts also present the happiness measurement through Yagyopathy. Much more research is possible through this in coming future.

\section{Acknowledgement}

The Team of authors would love to pay our deep sense of gratitude to the ABES Engineering College, Ghaziabad \& Amity International Business School, Amity University, and Noida for arranging us all the facilities, the direct-indirect supporters for their timely help and valuable suggestions and the almighty for blessing us throughout. We would also like to extend the vote of thanks to IIT Delhi, IIT Roorkee, Dev Sanskriti Vishwavidyalaya, Haridwar, Patanjali Foundation and Ayurveda Institute, Dehradun for their support and guidance in accomplishing our research paper.

\section{References}

1. Cameron A, Zimmet PZ, Dunstan DW, Dalton M, Shaw JE, et al. (2003) Overweight and obesity in Australia: the
1999-2000 Australian Diabetes, Obesity and Lifestyle Study (AusDiab). The Medical Journal of Australia 178(9): 427-432.

2. Chaturvedi DK, Satsangi R (2013) The Correlation between Student Performance and Consciousness Level, International Conference on Advanced Computing and Communication Technologies (ICACCT ${ }^{\text {TM }}$-2013), Asia Pacific Institute of Information Technology SD India, Panipat (Haryana) Souvenir, pp: 66.

3. Chaturvedi DK, Arya M (2013a) A Study of Correlation between Consciousness Level and Performance of Worker. Industrial Engineering Journal 6(8): 40-43.

4. Chaturvedi DK, Arya M (2013b) Correlation between Human Performance and Consciousness, IEEEInternational Conference on Human Computer Interaction, 23-24 Aug. 2013, Saveetha School of Engineering, Saveetha University, Thandalam, Chennai, IN, India.

5. Gunavathi C, Premalatha K (2014) A Comparative Analysis of Swarm Intelligence Techniques for Feature Selection in Cancer Classification. The Scientific World Journal 14: 12.

6. Jain G (2017) BLOG-Hawan for Cleansing the Environment.

7. Kim KJ, Tagkopoulos L (2019) Application of Machine Learning Rheumatic Disease Research. Korean J Intern Med 34(4): 708-722.

8. Lahoty P, Rana M (2013) Agnihotra organic farming. Popular Kheti 1(4): 49-54.

9. Mahajan P (2016) Application of Pattern Recognition Algorithm in Health and Medicine: a review. International Journal of Engineering and Computer Science 5(5): 16580-16583.

10. Marjani M, Nasaruddin F, Gani A, Karim A, Hashem IAT, et al. (2017) Big IoT Data Analytics: Architecture, Opportunities, and Open Research Challenges. IEEE Access 5: 5247-5261.

11. Rastogi R (2012) Current Approaches for Researches in Naturopathy: How far is its Evidence Base? J of Homeopathy \& Ayurvedic Medicine 1(2): 1-107.

12. Rastogi R, Chaturvedi DK, Sharma S, Bansal A, Agrawal A (2018a) Audio Visual EMG \& GSR Biofeedback Analysis for Effect of Spiritual Techniques on Human Behaviour and Psychic Challenges, in Proceedings of the $12^{\text {th }}$ INDIACom; INDIACom, pp: 252-258. 
13. Rastogi R, Chaturvedi DK, Satya S, Arora N, Sirohi H, et al. (2018b) Which one is Best: Electromyography Biofeedback Efficacy Analysis on Audio, Visual and Audio-Visual Modes for Chronic TTH on Different Characteristics, in the proceedings of International Conference on Computational Intelligence \& IoT (ICCIIoT) 2018, at National Institute of Technology Agartala, Tripura, India.

14. Rastogi R, Chaturvedi DK, Satya S, Arora N, Saini $\mathrm{H}$, et al. (2018c) Comparative Efficacy Analysis of Electromyography and Galvanic Skin Resistance Biofeedback on Audio Mode for Chronic TTH on Various Indicators, in the proceedings of International Conference on Computational Intelligence \& IoT (ICCIIoT) 2018,at National Institute of Technology Agartala, Tripura, India.

15. Mistry R, Tanwar S, Tyagi S, Kumar N (2020) Blockchain for 5G-Enabled IoT for Industrial Automation: A Systematic Review, Solutions, and Challenges, Mechanical Systems and Signal Processing, 135: 1-19.

16. Shenwai MR, Tare KN (2017) Integrated Approach towards Holistic Health: Current Trends and Future Scope. Int J of Cur Rec Rev 9(7): 11-14.

17. Rastogi R, Chaturvedi DK, Verma H, Mishra Y, Gupta M (2020a) Identifying Better? Analytical Trends to Check Subjects' Medications Using Biofeedback Therapies. IGL Global, International Journal of Applied Research on Public Health Management 5(1): 1-18.

18. Rastogi R, Gupta M, Chaturvedi DK (2020b) Efficacy of Study for Correlation ofTTH vs Age and Gender Factors using EMG Biofeedback Technique. International Journal of Applied Research on Public Health Management 5(1): 49-66.

19. Rastogi R, Chaturvedi DK, Satya S, Arora N, Gupta M, et al. (2020c) An Optimized Biofeedback EMG and GSR Biofeedback Therapy for Chronic TTH on SF-36 Scores of Different MMBD Modes on Various Medical Symptoms,in Studies Comp. Intelligence, Vol. 841: Hybrid Machine Intelligence for Medical Image Analysis.

20. Rastogi R, Saxena M, Sharma SK, Muralidharan S, Beriwal VK, et al. (2019a) Evaluation of Efficacy of Yagya Therapy on T2- Diabetes Mellitus Patients, in the proceedings of The $2^{\text {nd }}(E d n$.), of International Conference on Industry Interactive Innovations in Science, Engineering and Technology (I3SET2K19) organized by JIS College of Engineering, Kalyani, West Bengal.

21. Rastogi R, Saxena M, Gupta US, Sharma S, Chaturvedi DK, et al. (2019b) Yajna and Mantra Therapy Applications on Diabetic Subjects: Computational Intelligence Based
Experimental Approach, in the proceedings of The 2nd edition of International Conference on Industry Interactive Innovations in Science, Engineering and Technology (I3SET2K19) organized by JIS College of Engineering, Kalyani, West Bengal.

22. Rastogi R, Saxena M, Sharma SK, Murlidharan S, Berival VK, et al. (2019c) Statistical Analysis on Efficacy of Yagya Therapy for Type- 2 Diabetic Mellitus Patients through Various Parameters, In: Das A, et al. (Eds.), on Computational Intelligence in Pattern Recognition (CIPR),Kalyani, West Bengal. Advs in Intelligent Syst., Computing, Vol. 1120, Computational Intelligence in Pattern, Recognition.

23. Saxena M, Sengupta B, Pandya P (2008) Controlling the Microflora in Outdoor Environment: Effect of Yagya. Indian Journal of Air Pollution Control 8(2): 30-36.

24. Saxena M, Kumar B, Matharu S (2018) Impact of Yagya on Particulate Matters. Interdisciplinary Journal of Yagya Research 1(1): 01-08.

25. Saxena M, Sharma SK, Muralidharan S, Beriwal V, Rastogi R, et al. (2020) Statistical Analysis Of Efficacy Of Yagya Therapy On Type-2 Diabetic Mellitus Patients on Various Parameters, In Proceedings of $2^{\text {nd }}$ International Conference on Computational Intelligence In Pattern Recognition (CIPR-2020), Institute Of Engineering And Management, Kolkata, West Bengal, India.

26. Sharma SR (2013) Shabd Brahma-Naad Brahm, BrahmVarchas, Shantikunj, pp: 55.

27. Sharma SR (2015a) Shabd Brahma-Naad Brahm, BrahmVarchas, Shantikunj, pp: 98.

28. Sharma SR (2015b) Gayatri MahaVigyan, BrahmVarchas, Shantikunj, pp: 235.

29. Sharma SR (2015c) Shabd Brahma-Naad Brahm, BrahmVarchas, Shantikunj, pp: 34

30. Sharma SR (2015d) Shabd Brahma-Naad Brahm, BrahmVarchas, Shantikunj, pp: 61

31. Shrivastava V, Batham L, Mishra A (2019) Yagyopathy (Yagya Therapy) for Various Diseases - An Overview. Ayurveda evam Samagra Swasthya Shodhamala 1(1): 1-11.

32. Srikanth (2019) 15 Benefits of machine learning in health care blog article.

33. Trust SG, Parivar G (2011) Yagya's effect on the environment blog article, UK. 
34. (2016) Strate School of Design, Paris, Singapore. IoT applications in healthcare, Supporting Robust Health and Medical Practices. Blog Article.
35. Verma S, Mishra A, Shrivastava V (2018) Yagya Therapy in vedic and ayurvedic literature: A Preliminary exploration. Interdisciplinary Journal of Yagya Research 1(1): 15-20.

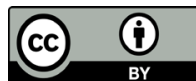

